\title{
Designing and Managing Value Co-Creation in KIBS Engagements
}

\author{
Lysanne Lessard
}

\author{
"The word VALUE, it is to be observed, has two different" \\ meanings, and sometimes expresses the utility of some \\ particular object, and sometimes the power of purchasing \\ other goods which the possession of that object conveys. \\ The one may be called "value in use;" the other, "value in \\ exchange." The things which have the greatest value in \\ use have frequently little or no value in exchange; on the \\ contrary, those which have the greatest value in exchange \\ have frequently little or no value in use.
}

Adam Smith (1723-1790)

Moral philosopher and "father of modern economics"

\begin{abstract}
Knowledge-intensive business services (KIBS) such as IT development, IT outsourcing, and research and development (R\&D) services have become a key component of most industrialized economies; they have been identified as an important source of employment growth in many countries and help improve the performance of firms belonging to most other sectors. KIBS have been discussed in innovation-related literature for over 15 years, with the assumption that models of innovation developed for manufacturing firms were not appropriate for them. This body of literature has also helped to identify the key characteristics and types of KIBS. However, although some empirical studies have investigated KIBS at the level of management - for example, how to manage customers' co-production processes - there has not been much research on how to successfully establish and manage engagements among KIBS providers, clients, and other collaborators. Moreover, informal conversations with KIBS professionals show that these activities are often approached in an ad hoc manner. Yet, given the importance of KIBS, taking a more systematic approach to their design and management could improve the contribution of knowledge-intensive business service activities to our economy.
\end{abstract}

This article proposes a framework for the design and management of KIBS engagements. The framework has been developed from a multiple-case study of academic R\&D service engagements, as one type of KIBS engagement. It consists of a set of information to be gathered and questions to be asked by professionals responsible for establishing, monitoring, and managing KIBS engagements. The information and questions are articulated around two key processes of collaborative value creation (or value co-creation) in KIBS engagements: i) the alignment of actors' interests, value propositions, and resources, and ii) the actors' ability to integrate the engagement's deliverables and outcomes as a basis for their perception of the engagement's value. Using this framework could help to establish more successful collaborations among KIBS providers, clients, and partners; it should also help to monitor the performance of a given KIBS engagement in terms of its collaborative processes, deliverables, and outcomes from the varied perspectives of participating parties. Although the framework accounts for these different and sometimes conflicting perspectives, it is intended to be used by KIBS provider firms whose success depends at least in part from their ability to manage collaborative relationships. 


\section{Designing and Managing Value Co-Creation in KIBS Engagements}

Lysanne Lessard

\section{Introduction}

There has been a surge in research on the nature of services (Delaunay \& Gadrey, 1992) as well as their design, management, and engineering over the past twenty years or so (e.g., Bullinger et al., 2003; Johns, 1999; Miles, 1993; Shostack, 1984; Solomon, 1985). The growing importance of the service sectors in industrialized economies, and of service activities within firms belonging to other sectors, made both industry and academia stand up and take notice (Chesbrough \& Spohrer, 2006). The major segment of revenue of many large organizations such as IBM, for example, have become the services that they provide around their products rather that the products by themselves (Spohrer \& Maglio, 2008). And, it has become generally agreed upon that the techniques and processes used to manage the production of goods are not fully adapted to the production of service activities, if at all (Chesbrough \& Spohrer, 2006).

As the introductory quotation shows, Adam Smith distinguished between two types of values: value-in-exchange and value-in-use. Crudely, the former means the price one puts on a good being sold in the marketplace, whereas the latter refers to the perceived value of that good (product or service) as it is being used by someone in a given context and for a given purpose. Whereas Smith focused on value-in-exchange to develop his well-known theories about nations' wealth, authors such as Normann (2001) and Vargo and Lusch (2004) argue that value-in-use is more relevant to understand service exchanges and the economy more generally. These arguments do not rely on a perceived inherent difference between the nature of goods and services; rather, they are proposed as a new understanding of how our modern economies have functioned all along. From this perspective, the rise of the service economy simply emphasizes the weaknesses in industrial-era theories of value. The concept of value co-creation is drawn from that of value-in-use; it states that value is always collaboratively created by interdependent actors in the market (providers, clients, partners, etc.), and that it is always determined by the beneficiary of the service (Ramirez, 1999; Vargo et al., 2008). At the core of this understanding is the view that value is not "added" by the producer, ready to be consumed by customers, but rather created collaboratively among actors (Ramirez, 1999).

A number of approaches for the design and management of service activities rely on the concept of value co-creation. However, these propositions are often based on illustrative or real-life examples of retail or otherwise business-to-customer (B2C) services (e.g., Patrício et al., 2011; Rosenbaum \& Massiah, 2011). Other propositions claim to be applicable to any type of business-to-business (B2B) service, without considering differences between, say, professional cleaning services and management consulting (e.g., Legner \& Vogel, 2007; Ordanini \& Pasini, 2008). Yet, one can identify varied service contexts (Glushko, 2009) and levels of design and management (e.g., internal service firm activities, networks of providers/clients). Although these approaches can be very useful for transactional service interactions or those with limited collaboration, they do not address important characteristics of highly collaborative, organization-to-organization service engagements.

Indeed, in this type of context, the boundary between front-end and back-end activities becomes blurred as actors across organizations jointly define and produce the service to be delivered. Moreover, in particular when the deliverable requires complementary areas of expertise, relationships are not established in a dyadic manner (provider and client), but in the form of a network: provider(s), client(s), third-party actor(s), funding or regulatory organization(s), etc. These relationships are then typically organized as medium- or long-term projects, or as more stable engagements such as alliances. Organizing the moments and activities in which network actors interact in this type of context can facilitate resource and information sharing; however, a more strategic, inter-organizational perspective is needed for the initial establishment of these relationships and their monitoring from the perspective of all involved parties.

\section{Knowledge-intensive business service engagements}

The type of highly collaborative, organization-to-organization service engagements described above are core to the service sector known as knowledge-intensive business services (KIBS). KIBS correspond to the subsector 54, "Professional, Scientific and Technical Activities" of the North American Industry Classification System (NAICS; tinyurl.com/o4stkje). This sector, which includes services such as R\&D, management consulting, and IT outsourcing, has become a key component of most industrialized economies (Strambach, 2001). KIBS have characteristics that distinguish them from other B2B services: they are knowledge-intensive in the sense that they rely on expert employees or provide knowledge-based solutions to their clients; clients are typically involved in the co-production of these solutions; and provider-client exchanges tend to be of a re- 


\section{Designing and Managing Value Co-Creation in KIBS Engagements}

Lysanne Lessard

lational rather than transactional nature (Bettencourt et al., 2002; Czarnitzki \& Spielkamp, 2003; Miles et al., 1995; Muller \& Doloreux, 2009).

KIBS have been discussed in innovation-related literature for over 15 years, with the assumption that models of innovation developed for manufacturing firms were not appropriate for them (Muller \& Doloreux, 2009). This body of literature often investigates the KIBS sector at the regional or national level, helping us to understand their importance in fostering innovation in industrialized economies. Firm-level studies of KIBS have also emphasized the importance of employees and clients in the co-production of knowledge-based service solutions (Bettencourt et al., 2002; Larsen, 2001) and the role of KIBS as transfer agents of innovation for their partners and other companies (Czarnitzki \& Spielkamp, 2003). Issues of knowledge management have been a key focus at that level. For example, it has been found that the knowledge needed by KIBS firms to create solutions for their clients and to innovate not only lies in each firm's individual employees but is created through their interactions with each other and with external collaborators (Larson, 2001). The competencies needed by KIBS providers to successfully process such knowledge thus extend beyond the mere transfer of knowledge to their client; they encompass the ability to transform knowledge from tacit to codified and back, to generalize from customer cases and apply locally from previous generalized knowledge, as well as to associate varied types of knowledge or dissociate needed dimensions (Gallouj, 2002). Despite these studies, however, much work remains to be done to support the design of KIBS at the (inter-) organizational level, thus to support the creation of successful KIBS engagements.

Value co-creation focuses on, among other things, knowledge and skills, the collaborative process between provider and client, and the wider space in which value is configured (Normann \& Ramirez, 1993; Vargo \& Lusch, 2008; Vargo et al., 2008). From this perspective, knowledge is given particular importance as a key operant resource (i.e., that acts on other resources), in contrast to operand resources (i.e., that are acted upon, such as natural resources) (Chesbrough \& Spohrer, 2006; Vargo \& Lusch, 2008). As such, the concept of value co-creation is in line with the core characteristics of KIBS. Yet, the way in which value co-creation actually happens in KIBS has not been extensively investigated as a basis for improving the management and design of that specific type of service. It is important to account for the particular context of KIBS because value co-creation processes, enablers, and inhibitors in the context of KIBS differ from those found in transactional services or those where collaboration is superficial (Sarker et al., 2012). Moreover, value co-creation processes in KIBS contexts are dynamic and complex (Stucky et al., 2011), which poses challenges that have yet to be fully addressed by current service design methods (Gkekas et al., 2012). This research addresses the conceptual gap between what we know about value cocreation and what we know about KIBS in current economies by presenting a framework derived from the understanding of value co-creation processes in the specific context of KIBS engagements.

\section{Methodology}

To understand what drives value co-creation in the specific context of KIBS engagements, a multiple-case study of two academic R\&D service engagements as one type of KIBS was undertaken. Although academic $R \& D$ services are not formally considered to belong to the KIBS sector as defined above, the cases selected for the study adhered to the key characteristics of KIBS: the academic partners relied on the expertise of participating faculty and students, and provided knowledgebased services to their clients; the latter were involved in co-producing the agreed-upon deliverables; and parties actively sought to develop long-term relationships with each other beyond the studied engagement. Moreover, the two cases can be categorized according to recognized types of KIBS, namely traditional professional services (P-KIBS) and technologically oriented services (T-KIBS), where new technology, in particular information and communication technology (ICT), is used intensively (Miles et al., 1995; Muller \& Doloreux, 2009). Indeed, the first case can be categorized as a TKIBS because it concerned the development of a virtual computer environment for a municipality, whereas the second case falls into the P-KIBS category because it concerned the creation of a new curriculum for health care aides.

The study was guided by key concepts of value co-creation identified in extant literature, but refined their understanding by identifying causal processes of value co-creation from data. The framework for the design and management of KIBS engagements presented in the following section was derived from the results of this research. Specifically, this research followed the explanation-building strategy of case study research, where tentative hypotheses generated from data in a single case can are revised through their application to successive cases (Yin, 1994). In each case study, key 


\section{Designing and Managing Value Co-Creation in KIBS Engagements}

Lysanne Lessard

stakeholders in the provider and client organizations were interviewed; meetings were also observed and project documentation was reviewed. Data were first coded using inductive grounded theory coding procedures (Charmaz, 2006). Emergent categories were then interpreted through key concepts of value co-creation identified in the literature, for example value propositions, resources, and valuing (Spohrer \& Maglio, 2010).

These categories, representing mechanisms of value cocreation processes, were then related into a conceptual framework of value co-creation, the first part of the design framework. This step was achieved through the identification of the properties of each category (i.e., what is concerned, who is involved, why, how and when this category comes into play, and the consequences of its activation). In order to guide the analysis of future KIBS engagements, the second part of the design framework focuses on the relationship between each pair of components, and between each causal process, to identify the design-oriented questions that this relationship suggested. In other words, given the way in which mechanisms and overall processes are related, which questions should be asked in order to successfully design relationships for KIBS engagements? For example, given that an actor's high-level interests have been found to shape the potential benefits it perceives from the engagement, one of the design questions seeks to evaluate the alignment between each actor's perceived benefits and high-level interests.

\section{Framework for the Design and Management of KIBS}

The framework is composed of two dimensions: descriptive and analytical. The descriptive dimension concerns the individual mechanisms that make the value co-creation processes evolve: developing high-level interests, perceiving benefits, creating value propositions, organizing resources, articulating deliverables, and valuing. These mechanisms become elements about which information needs be gathered by a KIBS professional wanting to establish, monitor, or improve a new or existing KIBS engagement. The analytical dimension concerns the relationships between each pair of mechanisms (e.g., the shaping of perceived benefits by an actor's high-level interests, the need to align one actor's value proposition with the benefits (potentially) perceived by another actor). This dimension consists of a series of questions to be asked about the engagement, whose answers should be derived from the information previously gathered.
Moreover, two key processes of value co-creation were identified through the study: aligning and integrating. The process of aligning connects the direct mechanisms developing high-level interests, perceiving benefits, creating value propositions, organizing resources, and articulating deliverables. All of these individual mechanisms need to be aligned in order for actors to commit to a service engagement. Indeed, if interactions and negotiations successfully lead to the development of value propositions that meet other actors' perceived benefits, and that necessitate resources whose cost is not greater than expected benefits, actors are likely to commit to the service engagement.

Each individual mechanism is itself a process, but what is key to value co-creation is how each one aligns with the others. A breakdown in any individual mechanism can cause a breakdown in the overall process of aligning. As, for example, actors realize that more resources are needed, or change their high-level interests, or give greater or lesser importance to the benefits they perceive, the alignment between mechanisms needs to be re-negotiated or re-established. Aligning is then a dynamic, continuous process throughout the service engagement. Commitment needs to happen for a service engagement to truly begin, but it frequently needs to be re-affirmed during the engagement as situations and actors change.

The process of integrating connects the individual mechanisms of developing high-level interests, perceiving benefits, articulating deliverables, valuing, and organizing resources. In an ideal scenario, these mechanisms are linked in a way that leads to a positive determination of value by actors. Specifically, the determination of value in KIBS engagements first emerges from the perception that the quality of the service engagement's deliverables and collaborative process meets actors' expectations (derived from perceived benefits); this dimension of valuing is conditional to the integration of deliverables and outcomes as resources. Second, it emerges from the perception that benefits actually, or planned to be, derived from integrating deliverables and outcomes as resources are in line with actors' high-level interests.

Breakdowns can happen at any point in the process: deliverables and outcomes may not meet expectations, actors may not be willing or able to integrate them as resources, or changes in an actor's high-level interests may render integration undesirable. Moreover, integration is not a monolithic process. Each actor integrates 


\section{Designing and Managing Value Co-Creation in KIBS Engagements}

\section{Lysanne Lessard}

only aspects of deliverables and outcomes that are perceived to be of interest. In some cases, it may be the outcomes of the engagement process - for example stronger relationships - rather than deliverables that are integrated. If the importance of these outcomes is high enough for the actor, it may still result in the perception that value has been created through the service engagement. These processes are not fully "phases" in an engagement, but the process of aligning comes first and must be successful for the process of integration to begin; however, aligning continues throughout the engagement.
Table 1 summarizes the elements about which information should be gathered in relation to each process. As stated in the table, information needs to be gathered about each actor taking part in the engagement. Indeed, the KIBS providers in the cases studied typically focused on issues of alignment with their client, sometimes at the expense of other actors such as third-party collaborators; this approach reduced commitments in time and other resources that negatively impacted deliverables and outcomes. Table 2 shows the questions that should be asked to increase alignment and support integration. Particular attention should be paid to the

Table 1. KIBS engagement information to be gathered in relation to each process

\section{Process Elements: Information to Gather}

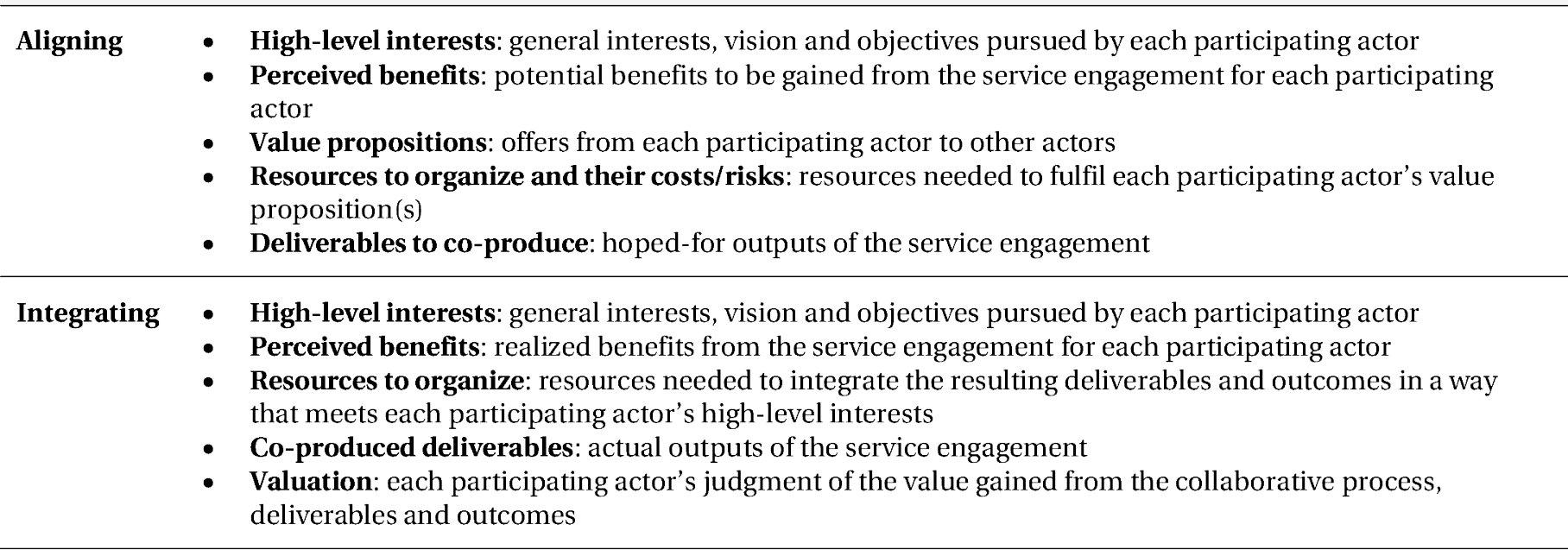

Table 2. Questions to ask to improve chances of success in a KIBS engagement

\begin{tabular}{|c|c|}
\hline Process & Questions \\
\hline Aligning & $\begin{array}{l}\text { - Is the value proposition of each actor well aligned with benefits of interest to the beneficiary actor? Are } \\
\text { there potential risks for each actor associated with another actor's value proposition? } \\
\text { - Are there other benefits that could better meet each actor's high-level interests? } \\
\text { - Do actors have the means to access, allocate, or create the resources required to fulfil their value } \\
\text { - Is the cost of resources required by each actor to fulfil its value proposition on par with the benefits that it } \\
\text { perceives from the engagement? }\end{array}$ \\
\hline Integrating & $\begin{array}{l}\text { What is the (likely) rating of the quality of co-produced deliverables by each actor? Which indicators may } \\
\text { be used as a basis for this judgment? } \\
\text { Which resources does each participating actor require to integrate these deliverables and the outcomes } \\
\text { from the collaborative process in a way that meets its high-level interests? Which indicators may be used to } \\
\text { judge the value hence created? }\end{array}$ \\
\hline
\end{tabular}




\section{Designing and Managing Value Co-Creation in KIBS Engagements}

\section{Lysanne Lessard}

issue of defining the indicators that will be used by each actor as a basis for judging the quality of deliverables and the value created by integrating these deliverables and the engagement's outcomes. The lack of explicitly defined and agreed-upon indicators was another typical issue in the cases studied, leading to sometimes surprising and often lower perceptions of value by clients than anticipated.

These findings are supported by other empirical research on the same topic. For example, another multiple-case study of value creation in T-KIBS engagements explained the emergence of perceived value as resulting from systems of "governing" (i.e., proposing value and authorizing the engagement) and "actualizing" (i.e., realizing the service and the resulting business value) (Stucky et al., 2011). Similar break points were identified in these processes, for example the client's failure to acknowledge any value because of a lack of alignment between the deliverable and the client's interests beyond the engagement. Findings and the resulting framework thus emphasize the strategic dimension of value co-creation; indeed, they show that value co-creation does not proceed solely from organizing resources, but must rather be understood from the high-level interests and perceived benefits of participating actors (Lessard \& Yu, 2013).

The information to gather and the questions to ask about resources to organize should be understood as encompassing both operant (e.g., knowledge) and operand (e.g., money) resources. Yet, knowledge remains one of the most important types of resources to organize to integrate deliverables and outcomes from the engagement, thus to co-create value (Ordanini \& Pasini, 2008). KIBS-specific knowledge-management activities such as knowledge acquisition, recombination, and transfer (Muller \& Zenker, 2001), and the knowledge competencies needed to accomplish them (Gallouj, 2002), thus undoubtedly play a critical role in ensuring the long-term success of KIBS provider firms. However, the framework proposed in this research lies at the strategic level of establishing and monitoring KIBS engagements, not at the level of daily knowledge-management activities.

Using this framework at the onset of an engagement could help KIBS professionals to ensure the commit- ment of clients and partners, and to put in place the elements needed for them to derive value from the engagement. The framework can also be used during an engagement to monitor the situation and take corrective actions if needed. Indeed, ensuring that each party comes out of an engagement with a positive perception of the value hence created is important not only for that particular engagement, but for their long-term willingness to collaborate.

\section{Conclusion}

This article has described a practical framework for KIBS professionals, tailored to their particular concerns. Indeed, it focuses on the processes and outcomes of value co-creation that are paramount to successful long-term relationships with clients and partners. As such, it is squarely aimed at addressing KIBS characteristics rather than transactional services or those leading to a superficial type of collaboration among parties. Moreover, this framework can help to establish and manage KIBS engagements in a more systematic and comprehensive manner than what is typically being done in KIBS contexts. Finally, it focuses on the strategic dimension of relationships (i.e., the "why") rather than on activities (i.e., the "how"). It can thus be used as a complement to process-based approaches such as service blueprinting (Bitner et al., 2008).

However, the results of this research are derived from a limited number of case studies set in only one type of KIBS (academic R\&D service engagements). This focus potentially limits the scope of applicability; indeed, different types of KIBS have been shown to differ in terms of patterns of innovation (Doloreux \& Shearmur, 2010), and they may thus differ in dynamics of value creation as well. Current research is underway to integrate the results of all existing empirical studies on value co-creation in KIBS engagement in order to strengthen and refine the framework presented in this article, as well as to broaden its scope of applicability. Another fruitful avenue for research would focus on the development of computer-supported tools to help gather and analyze information relevant to value co-creation and to visualize the results of analysis. Finally, further research should further investigate the interplay between value co-creation processes and knowledge-management processes in KIBS. 


\section{Designing and Managing Value Co-Creation in KIBS Engagements}

\section{Lysanne Lessard}

\section{About the Author}

Lysanne Lessard is Assistant Professor at the University of Ottawa's Telfer School of Management in Ottawa, Canada. Her research focuses on the development of design and modelling approaches for interorganizational contexts such as knowledge-intensive business service (KIBS) engagements. In these contexts, she investigates how organizational actors and ICTs form infrastructures in which information and knowledge are collaboratively created, shared, and transformed. This understanding leads to the creation of models, methods, and ICTs for the design, development, and evaluation of service systems. The results of this research enable greater value creation and innovation in today's networked economies.

\section{References}

Bettencourt, L. A., Ostrom, A. L., Brown, S. W., \& Roundtree, R. I. 2002. Client Co-Production in Knowledge-Intensive Business Services. California Management Review, 44(4): 100-128.

http://www.jstor.org/stable/41166145

Bitner, M. J., Ostrom, A. L., \& Morgan, F. N. 2008. Service Blueprinting: A Practical Technique for Service Innovation. California Management Review, 50(3): 66-94.

http://www.jstor.org/stable/41166446

Bullinger, H.-J., Fähnrich, K.-P., \& Meiren, T. 2003. Service Engineering-Methodical Development of New Service Products. International Journal of Production Economics, 85(3): 275-287. http://dx.doi.org/10.1016/S0925-5273(03)00116-6

Charmaz, K. 2006. Constructing Grounded Theory: A Practical Guide through Qualitative Analysis. Thousand Oaks, CA: Sage.

Chesbrough, H., \& Spohrer, J. 2006. A Research Manifesto for Services Science. Communications of the ACM, 49(7): 35-40. http://dx.doi.org/10.1145/1139922.1139945

Czarnitzki, D., \& Spielkamp, A. 2003. Business Services in Germany: Bridges for Innovation. Service Industries Journal, 23(2): 1-30. http://dx.doi.org/10.1080/02642060412331300862

Delaunay, J.-C., \& Gadrey, J. 1992. Services in Economic Thought: Three Centuries of Debate (A. Heesterman, Trans.). Boston: Kluwer Academic Publishers.

Doloreux, D., \& Shearmur, R. 2010. Exploring and Comparing Innovation Patterns across Different Knowledge Intensive Business Services. Economics of Innovation and New Technology, 19(7): 605 - 625. http://dx.doi.org/10.1080/10438590903128966

Gallouj, F. 2002. Knowledge-Intensive Business Services: Processing Knowledge and Producing Innovation. In J. Gadrey, \& F. Gallouj (Eds.), Productivity, Innovation and Knowledge in Services: New Economic and Socio-Economic Approaches: 256-284. Cheltenham: Edward Elgar.
Gkekas, K., Alcock, J., \& Tiwari, A. 2012. An Investigation of the Dynamic Features of Service Design Methods. Journal of Service Science Research, 4(2): 353-381. http://dx.doi.org/10.1007/s12927-012-0014-1

Glushko, R. J. 2009. Seven Contexts for Service System Design. In P. P. Maglio, C. A. Kieliszewski, \& J. C. Spohrer (Eds.), Handbook of Service Science: 219-249: Springer US.

Johns, N. 1999. What Is This Thing Called Service? European Journal of Marketing, 33(9/10): 958-973. http://dx.doi.org/10.1108/03090569910285959

Larsen, J. N. 2001. Knowledge, Human Resources and Social Practice: The Knowledge-Intensive Business Service Firm as a Distributed Knowledge System. Service Industries Journal, 21(1): 81-102. http://dx.doi.org/10.1080/714004998

Legner, C., \& Vogel, T. 2007. Design Principles for B2B Services - An Evaluation of Two Alternative Service Designs. In L. Zhang, \& P. Hung (Eds.), 2007 IEEE International Conference on Services Computing (SCC 2007): 372-379. Los Alamitos, CA: IEEE Computer Society.

Lessard, L., \& Yu, E. 2013. Service Systems Design: An Intentional Agent Perspective. Human Factors and Ergonomics in Manufacturing \& Service Industries, 23(1): 68-75. http://dx.doi.org/10.1002/hfm.20513

Miles, I. 1993. Services in the New Industrial Economy. Futures, 25(6): 653-672.

http://dx.doi.org/10.1016/0016-3287(93)90106-4

Miles, I., Kastrinos, N., Flanagan, K., Bilderbeek, R., \& Den Hertog, P. 1995. Knowledge-Intensive Business Services: Users, Carriers and Sources of Innovation. Brussels, Belgium: European Commission.

Muller, E., \& Doloreux, D. 2009. What We Should Know about Knowledge-Intensive Business Services. Technology in Society, 31(1): 6472.

http://dx.doi.org/10.1016/j.techsoc.2008.10.001

Muller, E., \& Zenker, A. 2001. Business Services as Actors of Knowledge Transformation: The Role of KIBS in Regional and National Innovation Systems. Research Policy, 30(9): 1501-1516. http://dx.doi.org/10.1016/S0048-7333(01)00164-0

Normann, R. 2001. Reframing Business: When the Map Changes the Landscape. Chichester: Wiley.

Normann, R., \& Ramirez, R. 1993. From Value Chains to Value Constellations. Harvard Business Review, 71(4): 65-77.

Ordanini, A., \& Pasini, P. 2008. Service Co-Production and Value CoCreation: The Case for a Service-Oriented Architecture (SOA). European Management Journal, 26(5): 289-297.

http://dx.doi.org/10.1016/j.emj.2008.04.005

Patrício, L., Fisk, R. P., Falcão e Cunha, J., \& Constantine, L. 2011. Multilevel Service Design: From Customer Value Constellation to Service Experience Blueprinting. Journal of Service Research, 14(2): 180-200.

http://dx.doi.org/10.1177/1094670511401901

Ramirez, R. 1999. Value Co-Production: Intellectual Origins and Implications for Practice and Research. Strategic Management Journal, 20(1): 49-65.

Rosenbaum, M. S., \& Massiah, C. 2011. An Expanded Servicescape Perspective. Journal of Service Management, 22(4): 471-490. http://dx.doi.org/10.1108/09564231111155088 


\section{Designing and Managing Value Co-Creation in KIBS Engagements}

\section{Lysanne Lessard}

Sarker, S., Sarker, S., Sahaym, A., \& Bjorn-Andersen, N. 2012. Exploring Value Cocreation in Relationships between an ERP Vendor and Its Partners: A Revelatory Case Study. MIS Quarterly: Management Information Systems, 36(1): 317-338.

Shostack, G. L. 1984. Designing Services That Deliver. Harvard Business Review, 62(1): 133-139.

Solomon, M. R. 1985. A Role Theory Perspective on Dyadic Interactions: The Service Encounter. Journal of Marketing, 49(1): 99.

Spohrer, J., \& Maglio, P. P. 2008. The Emergence of Service Science: Toward Systematic Service Innovations to Accelerate Co-Creation of Value. Production and Operations Management, 17(3): 238-246. http://dx.doi.org/10.3401/poms.1080.0027

Spohrer, J. C., \& Maglio, P. P. 2010. Toward a Science of Service Systems: Value and Symbols. In P. P. Maglio, C. A. Kieliszewski, \& J. C. Spohrer (Eds.), Handbook of Service Science: 157-194: Springer US.

Strambach, S. 2001. Innovation Processes and the Role of KnowledgeIntensive Business Services (KIBS). In K. Koschatzky, M. Kulicke, \& A. Zenker (Eds.), Innovation Networks, 12: 53-68: Physica-Verlag HD.
Stucky, S. U., Cefkin, M., Rankin, Y. A., Shaw, B., \& Thomas, J. O. 2011. Dynamics of Value Co-Creation in Complex IT Service Engagements. Information Systems and E-Business Management, 9(2): 267-281.

http://dx.doi.org/10.1007/s10257-010-0146-0

Vargo, S. L., \& Lusch, R. F. 2004. Evolving to a New Dominant Logic for Marketing. Journal of Marketing, 68(1): 1-17. http://dx.doi.org/10.1509/jmkg.68.1.1.24036

Vargo, S. L., \& Lusch, R. F. 2008. Service Dominant Logic: Continuing the Evolution. Journal of the Academy of Marketing Science, 36(1): $1-10$. http://dx.doi.org/10.1007/s11747-007-0069-6

Vargo, S. L., Maglio, P. P., \& Akaka, M. A. 2008. On Value and Value CoCreation: A Service Systems and Service Logic Perspective. European Management Journal, 26(3): 145-152. http://dx.doi.org/10.1016/j.emj.2008.04.003

Yin, R. K. 1994. Case Study Research: Design and Methods (Second ed.). Thousand Oaks: Sage. 